\title{
Voting in multi-stage elimination contests: Evidence from a karaoke show ${ }^{*}$
}

\author{
Ashley Durán ${ }^{\dagger} \quad$ César Mantilla ${ }^{\ddagger}$
}

May 3, 2021

\begin{abstract}
We employ the data from a karaoke contest to analyze strategic voting. Participants face a trade-off when voting for the contestant they want to eliminate. Excluding worst-performers increases the size of the prize allocated to the winner, whereas excluding top-performers increases the chances to become the winner. We analyze the performance and voting decisions and justifications of 138 participants in this contest across 23 episodes. We find that votes for worst-performers are much more common than votes for top-performers, and the justifications for voting due to the competitors' mistakes are the most prominent. Although contestants are not informed of the performance of themselves or any other participant, the likelihood to vote for the worst-performer is higher than the probability of randomly voting for someone else.
\end{abstract}

Keywords: competition, strategic voting

*Financial Support from the program "Inclusión productiva y social: programas y politicas para la promoción de una economía formal, código 60185, que conforma la Alianza EFI, bajo el Contrato de Recuperación Contingente No. FP44842-2202018." is gratefully acknowledged. Declarations of interest: None.

${ }^{\dagger}$ Department of Economics, Universidad del Rosario. e-mail: ashley.duran@urosario.edu.co

‡Department of Economics, Universidad del Rosario. e-mail: cesar.mantilla@urosario.edu.co 


\section{Introduction}

A contest can be regarded as an auction where participants make a costly bid, and an allocation rule assigns a set of prizes (Szymanski, 2003). This structure resembling a contest mimics familiar environments such as global conflicts, elections, sporting competitions, allocation of grants, and mate choice (Klumpp and Polborn, 2006; Dechenaux et al., 2015). In contrast to auctions, where allocation rules tend to favor the highest bidder unequivocally, the contest designer is not necessarily interested in a perfect mapping between effort and likelihood to win. For instance, in the particular case of the entertainment industry, the contestants' ability and the contest's unpredictability are factors of interest for the spectator, and the contest designer typically takes both into account (Szymanski, 2003), a trade-off known as competitive balance (Sanderson and Siegfried, 2003).

A widespread family of contests in sporting competitions and other entertainment formats are multi-stage elimination contests. Here, the parties compete over multiple stages, and some of them are sequentially eliminated until the prize allocation occurs. The prize allocation rule tends to have an implicit elimination rule, defining the eliminated parties of each stage based on performance. Theoretically, this elimination rule induces more effort compared to single-stage contests (Fu and $\mathrm{Lu}, 2012)$, and it is common in sporting competitions in the form of elimination brackets (e.g., in tennis, basketball, and soccer) or heats (e.g., in running and swimming).

A variation of this elimination rule, primarily employed in entertainment (e.g., reality shows), involves a voting procedure within each stage. Here, within-stage performance determines who is eligible for voting or for being voted. The sequential nature of this variation, where participants first perform and then vote, might distort the incentives to fully exert effort. Suppose, as will be the case in our data, that participants can vote for every contestant except for the stage's top-performer. Finishing in second place might lead to becoming the focal target of elimination, through voting, in that stage. Or in a more complex behavior, being the top performer in a given stage might turn this participant into the focal target of elimination in the following stage. This paper aims to understand better the voting patterns, and how the relative and absolute performance affect voting decisions.

Contests from TV shows have been previously employed as high-stakes natural experiments. Examples include the exploration of cooperation (Van den Assem et al., 2012), risk-taking (Post et al. 2008), best-response functions (Metrick, 1995), and gender differences (Linneman, 2013). We study voting patterns in a multi-stage contest, embedded in the karaoke show Sing On! from the platform Netflix.

In each episode, multiple contestants perform intervals of a shared song assigned to each stage. 
The more accurate they are in pitching the song, the larger the accumulated prize, which will be finally allocated to the last participant standing, the episode's winner. Initially, there are six contestants per episode. The show runs for five stages, with one contestant eliminated in each stage. In the first three stages, the remaining contestants must cast a vote for one of the team members, except the publicly announced top-performer of the stage. The contestant with the largest number of votes is eliminated. For the last two stages, the elimination of contestants employs an objective measure of performance related to the pitching accuracy. This pitching accuracy is also the tie-breaker criterion in the case of a tie in the voting stages.

We are interested in the voting behavior because participants face a trade-off. That is, we limit our scope to Stages 1 to 3 . Voting for stronger contestants increases their chance of winning the prize, whereas voting for weaker contestants increases the team's average performance, increasing the size of the final prize. The Sing On! contest offers two unique features that we exploit in our analysis. First, the objective measure of performance is revealed to the audience but not to the contestants. The only information before the voting stage is that the top performer, but not its absolute performance, is announced. Second, most of the contestants are asked about the reason for their vote before the eliminated contestant is revealed.

Whereas the main advantage of using data from Sing On! is the tournament structure from multiple episodes, the main drawback is the loss of control with respect to experimental settings. Hence, our analysis is primarily descriptive. We explore whether participants vote for the worstor top-performing contestants; and whether they justify their vote as punishing poor performers in the former case or aiming to eliminate top performers in the latter case. Note that, as contestants know neither about their own or any other contestant's performance-except for the stage's topperformer-the observed voting decision is based on each participant's detection ability of others' relative performance. Since our data includes three seasons of Sing On! from different countries, Germany, Spain, and the United States, we analyze cross-country differences in the detection of worst-and top-performers and the provided justifications for their vote.

We find that the likelihood that participants vote for the stage's worst-performer is larger than chance, and it is statistically significant in Stages 1 and 3. On the other hand, the probability of voting for the second-top-performer is lower than chance (and, again, it is statistically significant in Stages 1 and 3). However, it increases significantly between Stages 1 and 2. A regression analysis also reveals that participants with relatively lower performance (i.e., lower rank positions) are more likely to vote for the stage's second-top-performer. We find a similar result for the likelihood to vote for the winner of the previous stage.

We also find that the most common justification for a vote was a participant's mistake (45\%), followed by arguing that they vote against a strong competitor (18\%). By contrast, votes due 
to reciprocity (i.e., being voted in a previous stage) were rare $(2 \%)$. Besides, voting for a worstperformer is correlated with justifying the voting decision due to a participants' mistake. However, the voting justifications are not correlated with the votes for the second-top-performer.

The richness of sports data is often exploited for testing predictions from contest theory and game theory (Kahn, 2000: Walker and Wooders, 2001: Garicano et al., 2005: Palacios-Huerta, 2016). However, the empirical analyses of multi-stage contests are scarce. As an exception, Iqbal and Krumer (2019) explores the role of negative feedback in tennis and shows how the introduction of intermediate prizes reduced the discouragement effect. The additional evidence comes from laboratory experiments. Participants in two-stage contests tend to exert more significant efforts than predicted, a result that can be explained by the non-monetary utility of winning (Sheremeta, 2010; Altmann et al., 2012). Our results contribute with evidence of elimination outcomes that do not entirely depend on performance, leaving room for strategic voting.

The endogenous prize based on the contestants' performance connects our study with the team production literature. Field experiments exploring how to solve the inherent free-riding problem in team production have employed tournaments, team bonuses, and the revelation of relative feedback (Bandiera et al. 2013; Friebel et al., 2017; Song et al., 2018). Other mechanisms based on the exclusion of free-riders have been tested in laboratory experiments (Cinyabuguma et al., 2005. Maier-Rigaud et al. 2010), but their use in natural labor settings might be problematic. To some extent, and given the endogenous prize, elimination in the multi-stage contest that might lead to the exclusion of under-performers resembles an institution to exclude free-riders. We contribute to this literature by presenting a setting where worst-performers target top-performing contestants, even if this pattern might decrease the total earnings allocated to the winner.

\section{The Sing On! contest}

The music contest Sing On! is a Netflix original show. It debuted in July 2020 with Sing On! Spain, including eight episodes. It was followed by Sing On! Germany, aired in August 2020 with seven episodes. Lastly, Sing On! USA aired in September 2020 with eight episodes. Each episode starts with six contestants, usually three women and three men 1

Each episode consists of five stages. In each stage, all the participants who remain in competition collectively perform a song. Each song is selected by the show's producers beforehand, except for the final stage, where the penultimate stage's top-performer chooses the song between two alternatives. In Sing On! USA all the songs are performed in English. In Sing On! Spain and

\footnotetext{
${ }^{1}$ In Sing On! Germany there are two episodes in which all the contestants are from the same gender, one episode for women and one for men.
} 
Germany some songs are performed in English and others in Spanish and German, respectively. Song fragments are randomly assigned to contestants, who are rewarded based on their accuracy when performing the assigned fragments. A vocal analyzer compares each contestant's performance to the original artist and gives a score that the audience knows but remains unknown to the contestants.

The prize added to the jackpot in each stage depends on the participants' performance. This amount is proportional to the average participants' performance, multiplied by the stage's maximum price. In Stages 1 and 2 the maximum prize is USD 10,000 in Sing On! USA (and EUR 5,000 in Sing On! Spain and Germany). In Stages 3 and 4, the maximum prize is USD 15,000 (EUR 10,000) ${ }^{2}$ Stage 5 does not add money to the final prize, but rather defines the winner of this jackpot.

One participant is eliminated after each stage. During the first three stages, this elimination procedure occurs through a voting procedure. The remaining participants in the competition cast a vote directed to any other participant, except a vote to the stage's top-performer. The participant with the largest number of votes is eliminated. In case of a tie in the maximum number of votes, their performance is revealed, and the worst-performer among the tied participants is eliminated. After all the votes are cast, the show's host publicly asks each participant for whom they voted for and asks some of them their reasons for voting for the targeted participant. In the last two stages, the worst-performer is automatically eliminated. We collected data for 138 participants, 73 women and 65 men. Our data includes the participants' performance in each stage and the votes (and their reasons) for the first three stages.

\section{Results}

\subsection{Performance}

We find that the average performance is 0.653 , ranging from 0 to 1 . The differences in average performance between countries are relatively low: the United States has the highest average performance (0.664), followed by Spain (0.656) and Germany (0.636). Panel (a), in Figure 1, reveals how these differences between countries vary over the first three stages (where voting decisions are explored). In particular, while performance is increasing in the US, it is decreasing in Spain.

Regarding sex, average performance is similar between females (0.649) and males (0.658), and this difference is not significant ( $p$-value from a $t$-test is 0.429 ). These similarities are also observed across stages (see Panel (b) in Figure 1).

\footnotetext{
${ }^{2}$ Stage 4 also introduces an individual prize for each singer called a "Golden note." If the participant pitches a predefined note correctly, she instantly wins USD 1,000 (EUR 500).
} 

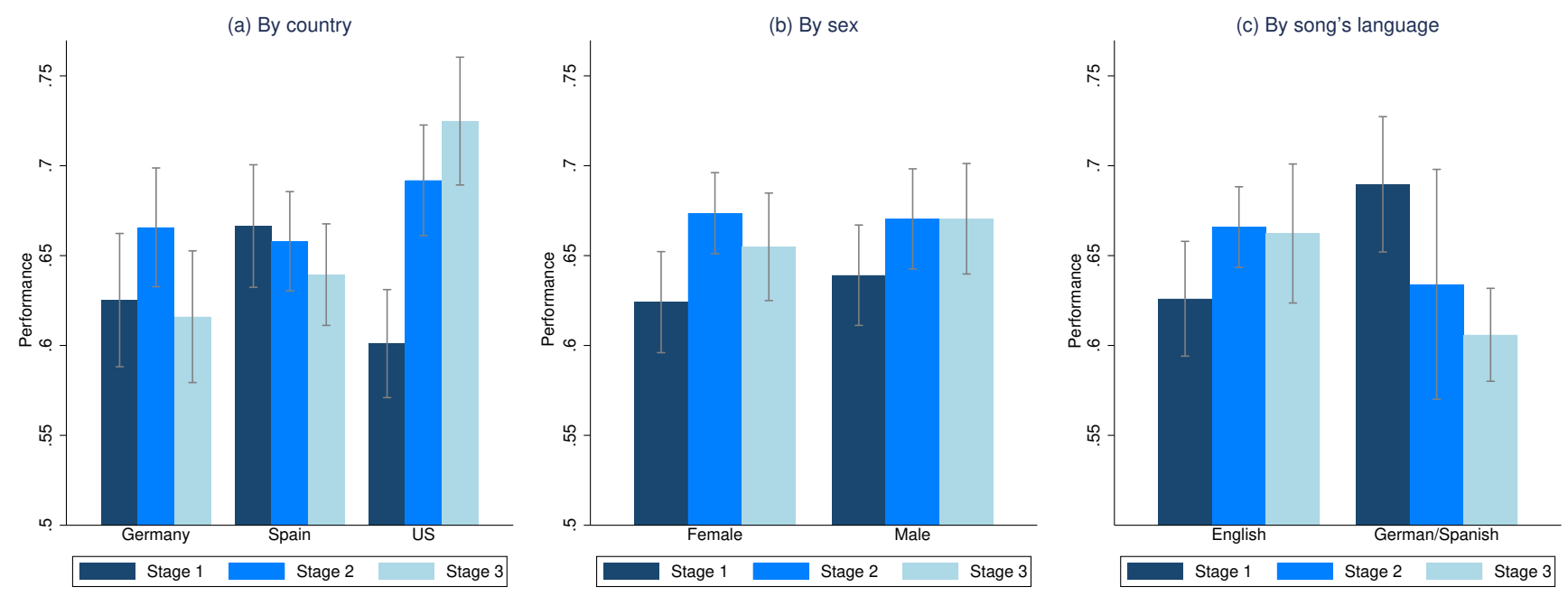

Figure 1: Average performance by country, sex and song's language, across Stages 1-3 of the contest

We also check whether performance differs when participants sing in their language (i.e., German or Spanish) or English. For this analysis and further comments regarding the song's language prior to the regressions, we omit the data from Sing On! USA. We observe a slightly lower performance when contestants sing in their language (0.650) with respect to English (0.668). Nonetheless, this difference is not statistically significant ( $p$-value from a $t$-test is 0.186). Panel (c) in Figure 1 confirms that there are no systematic differences in performance related to the song's language when the data is reported by stages.

We also compute the average standard deviation of the participants' performance within each stage of their episode, yielding 0.084. The average standard deviation is larger in Stage 1 (0.099) compared to Stages $2(0.081)$ and 3 (0.066). To give an idea of these deviations, a distribution of performances $0.75,0.70,0.65,0.60$, and 0.55 (i.e., the mean performance plus and minus 5 and 10 percentage points) would give a standard deviation of 0.079 . The average standard deviation is also larger for Spain (0.088), followed by the United States (0.082) and Germany (0.076). These differences are not statistically significant.

\subsection{Voting patterns}

We explore the voting decisions occurring in Stages 1 to 3. We are interested in whether participants voted for the stage's (i) worst-performer or (ii) the second-top performer.

The probability of voting for the stage's worst-performer is higher than chance (i.e., compared 

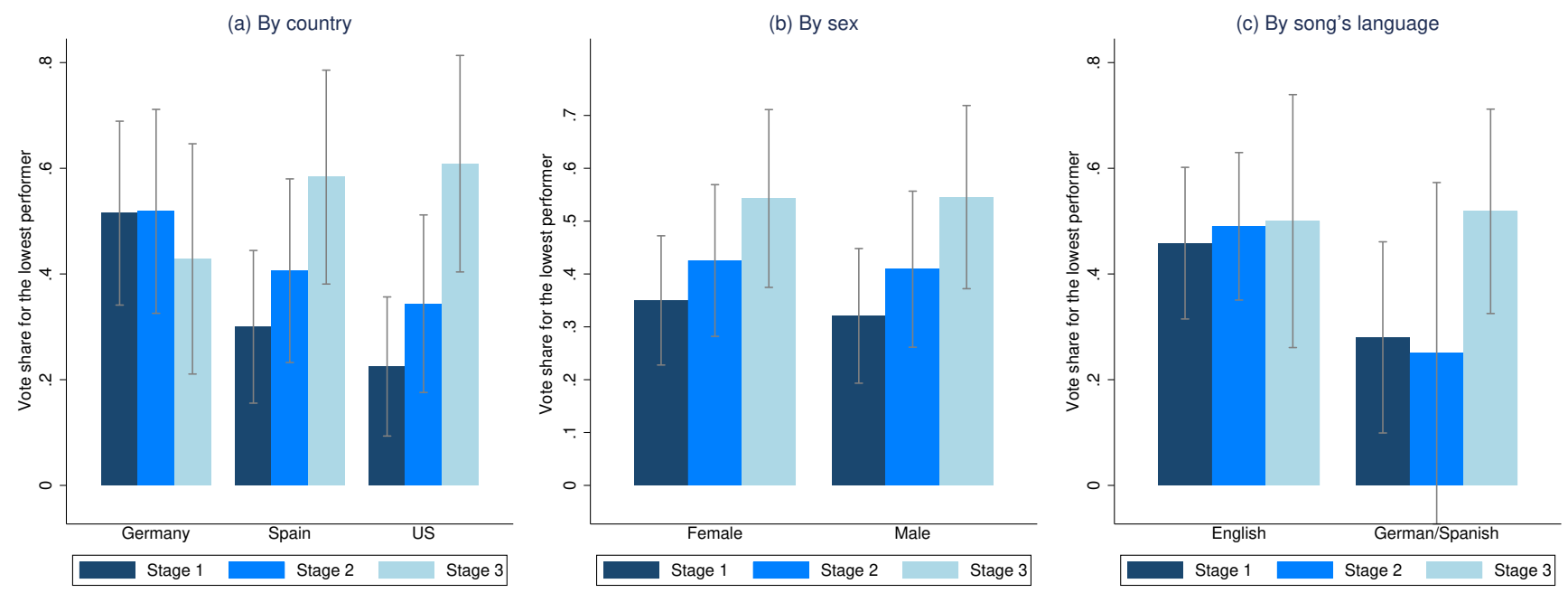

Figure 2: Vote share for the worst-performer by country, sex and song's language, across Stages 1-3 of the contest

to casting a random vote for a teammate, excluding herself and the stage's top-performer). However, its statistical significance is granted only in the earlier stage. In the first stage this probability is 0.333 ( $p$-value 0.056 against a $1 / 4$ chance of randomly voting for a teammate), in the second stage it is 0.418 ( $p$-value 0.109 against a $1 / 3$ chance), and in the third stage it is 0.544 ( $p$-value 0.471 against a $1 / 2$ chance).

Figure 2 depicts the share of votes for the worst-performer for each stage, by country, sex, and song's language. Panel (a) reveals that this vote share is different for Germany compared to Spain and the US. In the German case, the vote share starts at $51.5 \%$, the share remains similar in the second stage (51.9\%), and it decreases to $42.9 \%$ in the third stage. By contrast, in Spain and the United States, the vote share for the worst-performer is increasing: it goes from $30 \%$ to $41 \%$ to $58 \%$ for Spain, and from $21 \%$ to $34 \%$ to $61 \%$ for the United States.

Panel (b) does not reveal any particular difference between female and male voters in their likelihood to select the stage's worst-performer. This lack of a difference is confirmed with a $t$-test for the entire sample, yielding no difference by sex ( $p$-value 0.805). Panel (c), on the other hand, reveals a steeper increase in the vote share received by the worst-performer for the songs in the country's language. Moreover, the average vote share for worst-performer is higher for the songs performed in the other language (47.9\%) than in their language (38.3\%). However, this difference is not statistically significant ( $p$-value 0.229 using a $t$-test).

We move now to the description of the probability of voting for the second-top-performer. 
This outcome is of interest because, since contestants cannot vote for the top-performer, this is the best alternative if they opt to eliminate top performers that reduce their chances of winning the contest. We find that vote shares for the second-top-performer $(29.4 \%)$ are lower than the vote shares for the worst-performer (41.5\%). In Stage 1 it is $17.3 \%$ (versus $33.6 \%$ ), in Stage 2 it is $38.4 \%$ (versus $41.8 \%$ ), and in Stage 3 it is $36.8 \%$ (versus $54.4 \%$ ). This difference is statistically significant, excluding the votes from the second-top-performer and the worst-performer in Stages 1 and 3 ( $p$-values from a paired $t$-test are 0.041, 0.658, and 0.070 for Stages 1, 2, and 3, respectively). Moreover, these vote shares are also lower than chance in Stages 1 and 3 ( $p$-values from a one sample $t$-test are $0.035,0.320$ and 0.028 for Stages 1,2 , and 3, respectively).

Figure 3 depicts the share of votes for the second-top-performer for each stage, by country, sex, and song's language. The comparison across stages in all three panels confirms that votes for the second-top-performer increase in Stages 2 and 3. Panel (a) reveals a similar vote share across countries: a lower vote share in Stage 1 that roughly doubles (or triples in the US) in Stages 2 and 3. In panel (b), we observe that in Stage 1, the vote share for the second-top-performer is similar for men and women. However, in Stages 2 and 3, women appear to vote more frequently for the second-top-performer. This difference is not likely to be systematic since the $p$-value for a $t$-test comparing vote shares between men and women for Stages 2 and 3 is 0.090, before any correction for multiple hypothesis testing. Finally, panel (c) does not reveal differences in voting patterns for the second-top-performer related to the song's language.
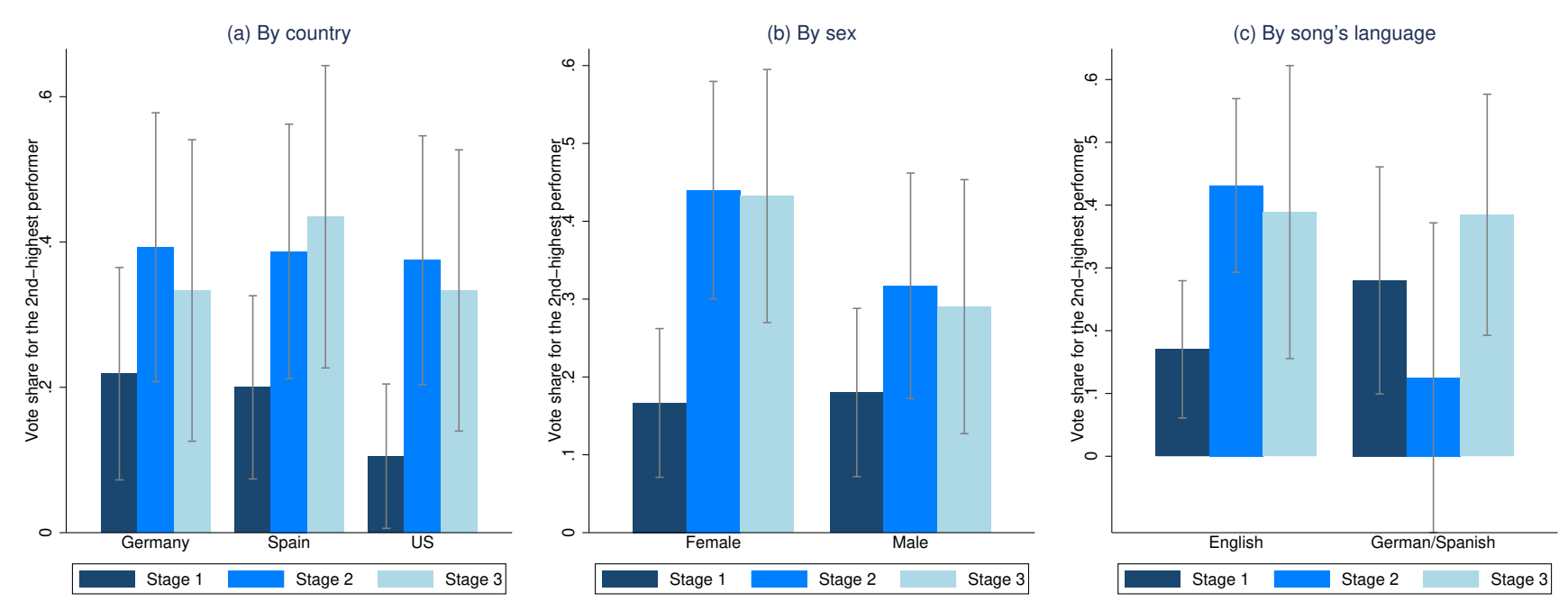

Figure 3: Vote share for the second-top-performer by country, sex and song's language, across Stages 1-3 of the contest 


\subsection{Justifications for voting decisions}

After all the participants cast their vote in each stage, the show's hosts asked all of them whom did they vote for. Moreover, the host asked most of the participants why did they make this choice. We coded the participants' explanation for their vote in five categories: (i) whether they attribute their vote to a mistake of the other $(45.2 \%)$, (ii) whether they considered the participant receiving their vote as a strong competitor for the price (18.3\%), (iii) whether they are reciprocating a vote received in a previous stage $(1.7 \%)$, (iv) whether they expressed it was a "default" vote $(5.5 \%)$, and (v) those participants for which their reasons for voting were not shown (29.3\%). Table A.1 shows that the only variable explaining whether a participant was not asked about the reason for her vote is the indicator variable for the US. Regressions including these reasons to vote as categorical variables are double-checked without the US sample.

Figure 4 shows the differences in the declared reasons for voting by stage, sex, country, and song's language, excluding the participants whose vote reason was not shown. Panel (a) reveals that votes associated with mistakes decrease, whereas the votes associated with eliminating strong contestants increase between Stages 2 and 3. The difference between stages is statistically significant ( $p$-value from a Pearson $\chi^{2}$ test is 0.001). Panel (b) reveals that the declared reasons for voting do not differ systematically between women and men ( $p$-value from a Pearson $\chi^{2}$ test is 0.351). Panel (c) reveals that votes associated with other participants' mistakes are more common in Spain $(60 \%)$ than in Germany $(41 \%)$ and the United States $(34 \%)$. In contrast, votes related to other participants' strength are more common in Germany $(24 \%)$ and the United States (19\%) than in Spain (13\%). The difference between countries is statistically significant ( $p$-value from a Pearson $\chi^{2}$ test lower than 0.001). Panel (d) reveals no statistical differences in the reasons given when we split the sample in the song's language ( $p$-value from a Pearson $\chi^{2}$ test is 0.610 ).

\subsection{Regression analysis}

Table 11 reports the coefficients of a linear probability model to predict the probability of voting for the worst-performer (columns 1-3) and the second-top-performer of each round (columns 46). Recall that participants do not know the absolute performance of the remaining competitors on the stage, meaning that voting for any of these two participants beyond chance implies some ability to detect good-or poor-contestants.

We start by describing the results for the probability of voting for the worst-performer. This probability does not significantly increase between Stages 1 and 2, but it is at least 20 percentage points larger in Stage 3 with respect to Stage 1. Nonetheless, this is a mechanical result. With fewer contestants every round, the chances of randomly selecting the worst-performer increase 
(a) By stage

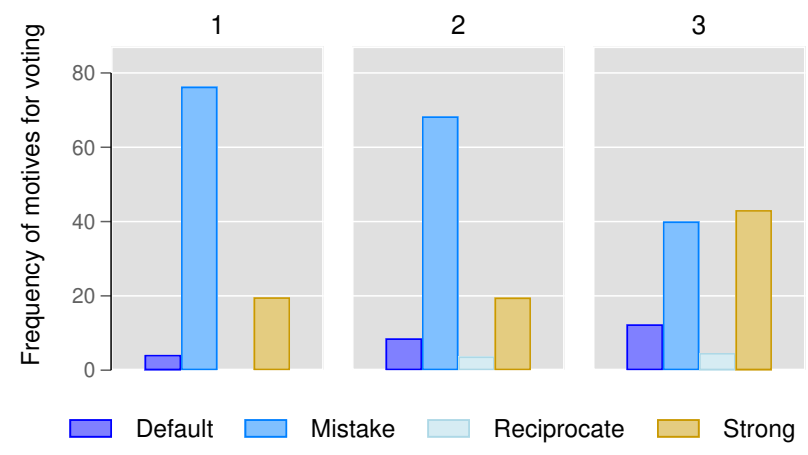

(c) By country

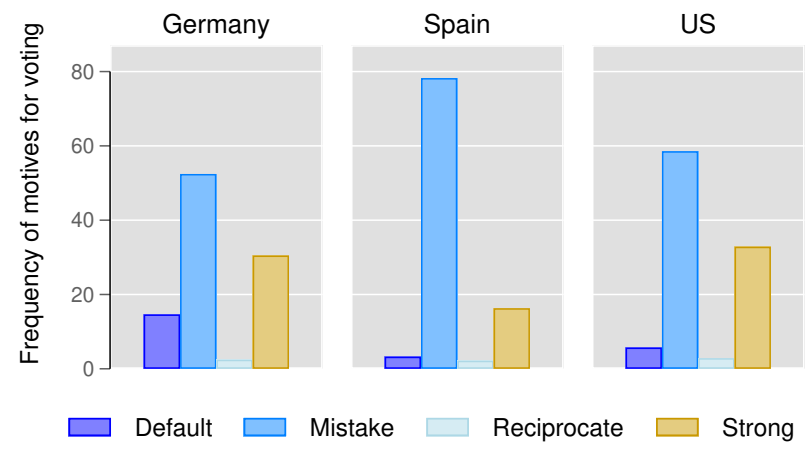

(b) By sex

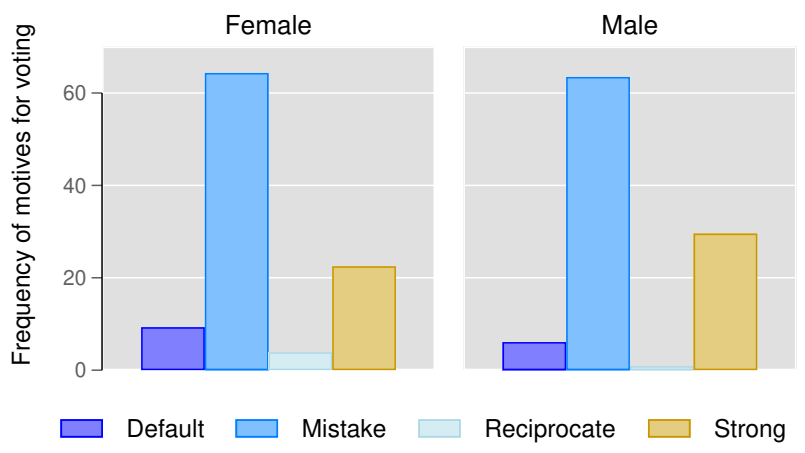

(d) By song's language

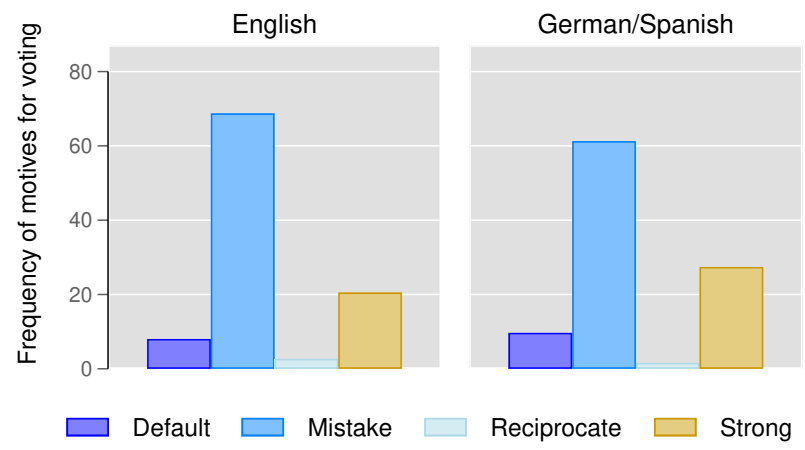

Figure 4: Coded frequency of reasons for voting by (a) Stage, (b) sex, (c) country, and (d) song's language.

over stages. The bottom of this table reports the $p$-values of an $F$ test for the marginal increases in the probability of randomly selecting a particular contestant, given that the number of participants is reduced between stages. These tests reveal that the increase in probabilities in Stages 2 and 3 does not differ from the mechanic marginal increase in probability.

The regression confirms the result from Figure 2 regarding cross-country differences: the probabilities of voting for the worst performer are lower in Spain and the US than in Germany. However, the coefficients are not systematically significant. Other predictors in columns 1 and 2, including performance (and its standard deviation), gender, song's language, and ranking (i.e., relative performance), are not statistically significant.

Column 3 shows that the declared reasons for voting are highly correlated with the probability of voting for the worst-performer. We observe a strong positive correlation between arguing a mis- 
Table 1: Regression analysis for the probability of voting for the worst-performer and the 2nd-topperformer

\begin{tabular}{|c|c|c|c|c|c|c|}
\hline \multirow[b]{2}{*}{ VARIABLES } & $(1)$ & $(2)$ & (3) & $(4)$ & $(5)$ & (6) \\
\hline & \multicolumn{3}{|c|}{ Pr(Vote Worst-Performer) } & \multicolumn{3}{|c|}{$\operatorname{Pr}$ (Vote 2nd-Top-Performer) } \\
\hline \multirow[t]{2}{*}{ Stage 2} & 0.0746 & 0.0716 & 0.115 & $0.219^{* * *}$ & $0.218^{* * *}$ & $0.220^{* * *}$ \\
\hline & $(0.0699)$ & $(0.0735)$ & $(0.0703)$ & $(0.0644)$ & $(0.0666)$ & $(0.0672)$ \\
\hline \multirow[t]{2}{*}{ Stage 3} & $0.201^{* * *}$ & $0.255^{* * *}$ & $0.394^{* * *}$ & $0.202^{* * *}$ & $0.247^{* * *}$ & $0.249^{* * *}$ \\
\hline & $(0.0756)$ & $(0.0867)$ & $(0.0867)$ & $(0.0698)$ & $(0.0782)$ & $(0.0802)$ \\
\hline \multirow[t]{2}{*}{ Performance } & 0.174 & 0.301 & 0.0828 & -0.152 & $0.620^{*}$ & $0.648^{*}$ \\
\hline & $(0.317)$ & $(0.393)$ & $(0.376)$ & $(0.247)$ & $(0.348)$ & $(0.351)$ \\
\hline \multirow[t]{2}{*}{ Male } & -0.0253 & -0.0241 & -0.0123 & -0.0706 & -0.0548 & -0.0601 \\
\hline & $(0.0596)$ & $(0.0597)$ & $(0.0568)$ & $(0.0548)$ & $(0.0543)$ & $(0.0548)$ \\
\hline \multirow[t]{2}{*}{ Spain } & -0.0910 & -0.0669 & $-0.163^{* *}$ & 0.0165 & 0.00799 & 0.0199 \\
\hline & $(0.0742)$ & $(0.0786)$ & $(0.0765)$ & $(0.0682)$ & $(0.0712)$ & $(0.0726)$ \\
\hline \multirow[t]{2}{*}{ United States } & $-0.138^{*}$ & -0.0440 & -0.0804 & -0.0487 & -0.0661 & -0.0433 \\
\hline & $(0.0744)$ & $(0.102)$ & $(0.0986)$ & $(0.0682)$ & $(0.0921)$ & $(0.0937)$ \\
\hline \multirow{2}{*}{ Song in own language } & & -0.123 & -0.0882 & & 0.00348 & -0.00784 \\
\hline & & $(0.0853)$ & $(0.0814)$ & & $(0.0772)$ & $(0.0776)$ \\
\hline \multirow[t]{2}{*}{ Ranking in stage [1-top] } & & 0.0204 & 0.0250 & & $0.0784^{* * *}$ & $0.0804^{* * *}$ \\
\hline & & $(0.0306)$ & $(0.0292)$ & & $(0.0246)$ & $(0.0247)$ \\
\hline \multirow[t]{2}{*}{ Std. Dev. of Performance } & & 0.449 & 0.561 & & -0.521 & -0.413 \\
\hline & & $(0.968)$ & $(0.920)$ & & $(0.892)$ & $(0.899)$ \\
\hline \multirow[t]{2}{*}{ Reason: Default } & & & $-0.440^{* * *}$ & & & 0.120 \\
\hline & & & $(0.143)$ & & & $(0.128)$ \\
\hline \multirow[t]{2}{*}{ Reason: Mistake } & & & $0.198^{* * *}$ & & & 0.0701 \\
\hline & & & $(0.0690)$ & & & $(0.0675)$ \\
\hline \multirow[t]{2}{*}{ Reason: Reciprocate } & & & 0.0958 & & & -0.125 \\
\hline & & & $(0.217)$ & & & $(0.207)$ \\
\hline \multirow[t]{2}{*}{ Reason: Strong } & & & $-0.198^{* *}$ & & & 0.121 \\
\hline & & & $(0.0894)$ & & & $(0.0814)$ \\
\hline \multirow[t]{2}{*}{ Constant } & 0.315 & 0.152 & 0.211 & $0.309^{*}$ & -0.418 & -0.516 \\
\hline & $(0.216)$ & $(0.333)$ & $(0.319)$ & $(0.160)$ & $(0.316)$ & $(0.323)$ \\
\hline Observations & 272 & 272 & 272 & 269 & 269 & 269 \\
\hline R-squared & 0.041 & 0.052 & 0.163 & 0.061 & 0.099 & 0.111 \\
\hline$p$-value $\beta_{\text {Stage } 2}=1 / 12$ & 0.9004 & 0.8733 & 0.6487 & 0.0358 & 0.0446 & 0.0432 \\
\hline$p$-value $\beta_{\text {Stage } 3}-\beta_{\text {Stage } 2}=1 / 6$ & 0.6102 & 0.8467 & 0.179 & 0.0109 & 0.0758 & 0.0794 \\
\hline$p$-value $\beta_{\text {Stage } 3}-\beta_{\text {Stage } 2}=0$ & & & & 0.8101 & 0.7002 & 0.7149 \\
\hline
\end{tabular}


take from the targeted participant and the actual vote for the worst-performer. In the same spirit, there is also a negative correlation between declaring that the vote went to a strong contestant and voting for the worst-performer.

Regarding the probability of voting for the second-top-performer, reported in columns 4 to 6, we find that the probability increase between Stages 1 and 2 is larger than the mechanical increase by chance, in about 14 percentage points. By contrast, the probability increase between Stages 2 and 3 is not different from zero. In other words, it increases below the expected mechanical increase of choosing a random participant to vote for.

Columns 5 and 6 reveal two significant predictors of the probability of voting for the secondtop-performer: absolute performance and relative performance (i.e., the ranking) in each stage. The coefficient for performance is positive and marginally significant, suggesting a strong correlation between higher absolute performance and voting for the available good contestants. Moreover, the coefficient of the ranking variable is also positive and significant, indicating that lowering a position (i.e., getting farther from the top place, coded as 1) also increases the probability of voting for the second-top-performer. Since these two coefficients appear to reveal contradictory effects, we conduct two additional regressions. We split the sample into the top performers of each and the third-to-last performers in each stage. The results (see Table A.2 in the Appendix) reveal that the statistical significance of the coefficient for performance is driven by the top performer, whereas the remaining participants drive the statistical significance of the ranking.

On the other hand, and unlike the analysis for the probability of voting for the worst-performer, the reported reasons for voting are not statistically significant in columns 4 to 6 . Indicator variables for the countries, the contestant's sex, or the song's language are neither significant.

Table 1 describes some results regarding the detection of worst and top-performers. Whereas in this exercise the signals of contestants' performance are noisy, we now proceed with an analysis in which contestants can employ perfect signals of past performance. In particular, we run a regression on the determinants of voting for the winner of the previous stage. This event occurred $19 \%$ of the times in Stage 2 and 23\% of the times in Stage 3. Table A.3, in the Appendix, reveals that performance is strongly and negatively correlated with the probability of voting for the last stage's winner. This correlation suggests that competitors are likely to use past and clear signals of good competitors in cases of low performance. Moreover, we also find a positive correlation between claiming that the reason for voting was the contestant's strength and targeting the past winner. On the other hand, we do not find differences between Stages 2 and 3 on the likelihood to vote for a past winner.

As a final robustness exercise, we exclude the US sample from the regressions include the declared reasons for voting as covariates. Recall from Table A.1 that the only variable that predicts 
the probability that the contestant was not asked about the reason for her vote is the categorical variable for the US. Table A.4 shows that the results are similar after excluding the US sample. The single coefficient with a reduced magnitude and significance is the indicator variable for participants declaring their vote targeted strong contestants.

\section{Conclusions}

We employ data from a Karaoke contest to study strategic voting in a multi-stage elimination contest. In this contest, voters face a trade-off between eliminating worst-performers, aiming to raise the total amount received by the winner, and eliminating top-performers, increasing their chances to win. We collected and used the data from 138 participants of the Sing On! contest, from a total of 23 episodes from three different countries. We find that participants vote for worstperformers with a probability higher than the chance of randomly selecting a competitor. By contrast, the probability of voting for the second-top-performer (as votes cannot be cast for the top-performer) is lower than the chance associated with a random vote. Hence, contestants appear to be inclined to eliminate worst-performers to increase the prize awarded to the winner.

This result is interesting because participants were not informed about their own or the other contestants' performance. Hence, votes for the worst-performers appear to signal good detection abilities, which are then employed to exclude them from the contest. This behavior is confirmed by the large proportion of justifications for votes associated with other competitors' mistakes when pitching the song.

Although the votes for top-performers occur with a lower likelihood, the regression analysis reveals two results that, at first sight, seem contradictory. Absolute performance is positively correlated, whereas the relative performance (i.e., ranking in the stage) is negatively correlated with the chances of voting for the second-top-performer. Two additional regression analyses shed light on reconciling these results. We find that top-performers rely on the signal of absolute performance, whereas worst-performers rely on the signal of relative performance. Besides, worstperformers are more likely to vote for top-performers when receiving more precise signals, such as who was the winner of a previous stage.

Despite the evidence of gender differences in competitive environments (Gneezy et al., 2003. 2009: Kleinjans, 2009: Niederle and Vesterlund, 2010), even in other TV contests (Linneman, 2013), we do not find any differences in performance, nor in voting patterns, between women and men. We offer two conjectures for the absence of differences. First, there might be a strong selection into the contest, guaranteeing that women and men are highly competitive. Second, since singing is not a stereotypical male task, it reduces the effects of differences in confidence that ultimately 
affect behavior (Fryer Jr and Levitt, 2010; Niederle and Vesterlund, 2011).

\section{References}

Altmann, S., Falk, A., and Wibral, M. (2012). Promotions and incentives: The case of multistage elimination tournaments. Journal of Labor Economics, 30(1):149-174.

Bandiera, O., Barankay, I., and Rasul, I. (2013). Team incentives: Evidence from a firm level experiment. Journal of the European Economic Association, 11(5):1079-1114.

Cinyabuguma, M., Page, T., and Putterman, L. (2005). Cooperation under the threat of expulsion in a public goods experiment. Journal of Public Economics, 89(8):1421-1435.

Dechenaux, E., Kovenock, D., and Sheremeta, R. M. (2015). A survey of experimental research on contests, all-pay auctions and tournaments. Experimental Economics, 18(4):609-669.

Friebel, G., Heinz, M., Krueger, M., and Zubanov, N. (2017). Team incentives and performance: Evidence from a retail chain. American Economic Review, 107(8):2168-2203.

Fryer Jr, R. G. and Levitt, S. D. (2010). An empirical analysis of the gender gap in mathematics. American Economic Journal: Applied Economics, 2(2):210-40.

Fu, Q. and Lu, J. (2012). The optimal multi-stage contest. Economic Theory, 51(2):351-382.

Garicano, L., Palacios-Huerta, I., and Prendergast, C. (2005). Favoritism under social pressure. Review of Economics and Statistics, 87(2):208-216.

Gneezy, U., Leonard, K. L., and List, J. A. (2009). Gender differences in competition: Evidence from a matrilineal and a patriarchal society. Econometrica, 77(5):1637-1664.

Gneezy, U., Niederle, M., and Rustichini, A. (2003). Performance in competitive environments: Gender differences. The Quarterly Journal of Economics, 118(3):1049-1074.

Iqbal, H. and Krumer, A. (2019). Discouragement effect and intermediate prizes in multi-stage contests: Evidence from davis cup. European Economic Review, 118:364-381.

Kahn, L. M. (2000). The sports business as a labor market laboratory. Journal of Economic Perspectives, 14(3):75-94.

Kleinjans, K. J. (2009). Do gender differences in preferences for competition matter for occupational expectations? Journal of Economic Psychology, 30(5):701-710. 
Klumpp, T. and Polborn, M. K. (2006). Primaries and the new hampshire effect. Journal of Public Economics, 90(6-7):1073-1114.

Linneman, T. J. (2013). Gender in Jeopardy! intonation variation on a television game show. Gender $\mathcal{E}$ Society, 27(1):82-105.

Maier-Rigaud, F. P., Martinsson, P., and Staffiero, G. (2010). Ostracism and the provision of a public good: experimental evidence. Journal of Economic Behavior E Organization, 73(3):387-395.

Metrick, A. (1995). A natural experiment in “Jeopardy!". American Economic Review, 85(1):240-253.

Niederle, M. and Vesterlund, L. (2010). Explaining the gender gap in math test scores: The role of competition. Journal of Economic Perspectives, 24(2):129-44.

Niederle, M. and Vesterlund, L. (2011). Gender and competition. Annu. Rev. Econ., 3(1):601-630.

Palacios-Huerta, I. (2016). Beautiful game theory: How soccer can help economics. Princeton University Press.

Post, T., Van den Assem, M. J., Baltussen, G., and Thaler, R. H. (2008). Deal or no deal? decision making under risk in a large-payoff game show. American Economic Review, 98(1):38-71.

Sanderson, A. R. and Siegfried, J. J. (2003). Thinking about competitive balance. Journal of Sports Economics, 4(4):255-279.

Sheremeta, R. M. (2010). Experimental comparison of multi-stage and one-stage contests. Games and Economic Behavior, 68(2):731-747.

Song, H., Tucker, A. L., Murrell, K. L., and Vinson, D. R. (2018). Closing the productivity gap: Improving worker productivity through public relative performance feedback and validation of best practices. Management Science, 64(6):2628-2649.

Szymanski, S. (2003). The economic design of sporting contests. Journal of Economic Literature, 41(4):1137-1187.

Van den Assem, M. J., Van Dolder, D., and Thaler, R. H. (2012). Split or steal? cooperative behavior when the stakes are large. Management Science, 58(1):2-20.

Walker, M. and Wooders, J. (2001). Minimax play at Wimbledon. American Economic Review, 91(5):1521-1538. 


\section{Appendix}

\section{A Additional Tables}

Table A.1: Linear probability model for whether the contestant was not asked about the reason for her vote.

\begin{tabular}{lcc}
\hline & $(1)$ & $(2)$ \\
VARIABLES & $\operatorname{Pr}($ Reason was not asked) \\
\hline & & \\
Stage (Continuous) & 0.00584 & \\
Stage 2 & $(0.0342)$ & \\
& & -0.0114 \\
Stage 3 & & $(0.0600)$ \\
& & 0.0152 \\
Performance & -0.387 & $(0.0691)$ \\
& $(0.312)$ & -0.372 \\
Male & -0.0104 & $(0.315)$ \\
Spain & $(0.0488)$ & -0.0103 \\
& 0.0461 & $(0.0488)$ \\
United States & $(0.0638)$ & 0.0477 \\
Song in own language & $0.275^{* * *}$ & $(0.0641)$ \\
& $(0.0817)$ & $0.280^{* * *}$ \\
Ranking in stage [1-top] & -0.0821 & $(0.0830)$ \\
Std. Dev. of Performance & $(0.0670)$ & -0.0887 \\
Constant & 0.00127 & $(0.0697)$ \\
& $(0.0225)$ & 0.00198 \\
R-squared & -0.306 & $(0.0227)$ \\
& $(0.791)$ & -0.316 \\
Standard & $0.496^{*}$ & $(0.792)$ \\
& $(0.291)$ & $0.497^{*}$ \\
& & $(0.279)$ \\
& 345 & 345 \\
& 0.053 & 0.053 \\
\hline
\end{tabular}

Standard errors in parentheses. ${ }^{* *} \mathrm{p}<0.01,{ }^{* *} \mathrm{p}<0.05,{ }^{*} \mathrm{p}<0.1$ 
Table A.2: Regression analysis for the probability of voting for the 2nd-top-performer divided by the voter's ranking.

\begin{tabular}{|c|c|c|}
\hline \multirow[b]{3}{*}{ VARIABLES } & \multirow{2}{*}{\multicolumn{2}{|c|}{$\begin{array}{cc}(1) & (2) \\
\operatorname{Pr}(\text { Vote 2nd-top-performer) }\end{array}$}} \\
\hline & & \\
\hline & Ranked 1st & Ranked 3rd-Last \\
\hline \multirow[t]{2}{*}{ Stage 2} & -0.102 & $0.320^{* * *}$ \\
\hline & $(0.125)$ & $(0.0817)$ \\
\hline \multirow[t]{2}{*}{ Stage 3} & -0.0356 & $0.332^{* * *}$ \\
\hline & $(0.142)$ & $(0.104)$ \\
\hline \multirow{2}{*}{ Performance } & $1.300^{*}$ & 0.599 \\
\hline & $(0.702)$ & $(0.444)$ \\
\hline \multirow{2}{*}{ Ranking in stage [1-top] } & & $0.0795^{*}$ \\
\hline & & $(0.0452)$ \\
\hline \multirow[t]{2}{*}{ Constant } & -0.426 & -0.613 \\
\hline & $(0.497)$ & $(0.461)$ \\
\hline Observations & 69 & 200 \\
\hline R-squared & 0.171 & 0.132 \\
\hline \multicolumn{3}{|c|}{$\begin{array}{l}\text { Controls included: standard deviation of performance, and } \\
\text { indicator variables for sex, country, song's language, and } \\
\text { reasons to vote for the targeted participant. Standard errors in } \\
\text { parentheses. }{ }^{* *} \mathrm{p}<0.01,{ }^{* *} \mathrm{p}<0.05,{ }^{*} \mathrm{p}<0.1\end{array}$} \\
\hline
\end{tabular}


Table A.3: Regression analysis for the probability of voting for the winner in the past stage

\begin{tabular}{|c|c|c|c|}
\hline & (1) & $(2)$ & (3) \\
\hline VARIABLES & \multicolumn{3}{|c|}{$\operatorname{Pr}($ Vote Previous Winner $)$} \\
\hline Stage 3 & $\begin{array}{l}-0.0791 \\
(0.0712)\end{array}$ & $\begin{array}{l}-0.0488 \\
(0.0813)\end{array}$ & $\begin{array}{l}-0.0280 \\
(0.0820)\end{array}$ \\
\hline Performance & $\begin{array}{c}-1.623^{* * *} \\
(0.400)\end{array}$ & $\begin{array}{c}-1.394^{* * *} \\
(0.506)\end{array}$ & $\begin{array}{c}-1.678^{* * *} \\
(0.509)\end{array}$ \\
\hline Male & $\begin{array}{l}-0.0607 \\
(0.0673)\end{array}$ & $\begin{array}{l}-0.0723 \\
(0.0679)\end{array}$ & $\begin{array}{l}-0.0649 \\
(0.0659)\end{array}$ \\
\hline Spain & $\begin{array}{c}0.136 \\
(0.0967)\end{array}$ & $\begin{array}{c}0.147 \\
(0.0988)\end{array}$ & $\begin{array}{c}0.132 \\
(0.0979)\end{array}$ \\
\hline United States & $\begin{array}{l}0.222^{* *} \\
(0.0860)\end{array}$ & $\begin{array}{c}0.191 \\
(0.160)\end{array}$ & $\begin{array}{c}0.219 \\
(0.156)\end{array}$ \\
\hline Song in own language & & $\begin{array}{c}-0.0120 \\
(0.137)\end{array}$ & $\begin{array}{l}-0.0746 \\
(0.135)\end{array}$ \\
\hline Ranking in stage [1-top] & & $\begin{array}{c}0.0408 \\
(0.0380)\end{array}$ & $\begin{array}{c}0.0437 \\
(0.0368)\end{array}$ \\
\hline Std. Dev. of Performance & & $\begin{array}{c}1.699 \\
(1.229)\end{array}$ & $\begin{array}{l}1.966 \\
(1.216)\end{array}$ \\
\hline Reason: Default & & & $\begin{array}{l}-0.0523 \\
(0.127)\end{array}$ \\
\hline Reason: Mistake & & & $\begin{array}{c}0.113 \\
(0.0834)\end{array}$ \\
\hline Reason: Reciprocate & & & $\begin{array}{l}0.0500 \\
(0.171)\end{array}$ \\
\hline Reason: Strong & & & $\begin{array}{l}0.287^{* * *} \\
(0.0925)\end{array}$ \\
\hline Last Winner is the Worst & $\begin{array}{c}0.0905 \\
(0.0996)\end{array}$ & $\begin{array}{c}0.140 \\
(0.104)\end{array}$ & $\begin{array}{c}0.138 \\
(0.100)\end{array}$ \\
\hline Constant & $\begin{array}{c}1.352^{* * *} \\
(0.309)\end{array}$ & $\begin{array}{l}0.919^{* *} \\
(0.445)\end{array}$ & $\begin{array}{l}0.981^{* *} \\
(0.431)\end{array}$ \\
\hline $\begin{array}{l}\text { Observations } \\
\text { R-squared }\end{array}$ & $\begin{array}{c}97 \\
0.212\end{array}$ & $\begin{array}{c}97 \\
0.240\end{array}$ & $\begin{array}{c}97 \\
0.329\end{array}$ \\
\hline
\end{tabular}

Standard errors in parentheses. ${ }^{* * *} \mathrm{p}<0.01,{ }^{* *} \mathrm{p}<0.05,{ }^{*} \mathrm{p}<0.1$ 
Table A.4: Robustness checks excluding the US sample from regressions with the reported reasons for voting as covariates

\begin{tabular}{|c|c|c|c|}
\hline VARIABLES & $\begin{array}{l}\text { Pr(Vote Worst- } \\
\text { Performer) }\end{array}$ & $\begin{array}{c}\text { Pr(Vote } \\
\text { 2nd-Top- } \\
\text { Performer) }\end{array}$ & $\begin{array}{c}\text { Pr(Vote } \\
\text { Previous } \\
\text { Winner) }\end{array}$ \\
\hline Stage 2 & $\begin{array}{c}0.0953 \\
(0.0934)\end{array}$ & $\begin{array}{l}0.213^{* *} \\
(0.0896)\end{array}$ & \\
\hline Stage 3 & $\begin{array}{l}0.296^{* *} \\
(0.120)\end{array}$ & $\begin{array}{c}0.308^{* * *} \\
(0.113)\end{array}$ & $\begin{array}{l}-0.134 \\
(0.129)\end{array}$ \\
\hline Performance & $\begin{array}{r}-0.0879 \\
(0.527)\end{array}$ & $\begin{array}{l}0.855^{*} \\
(0.479)\end{array}$ & $\begin{array}{c}-1.831^{* *} \\
(0.827)\end{array}$ \\
\hline Male & $\begin{array}{l}0.00432 \\
(0.0743)\end{array}$ & $\begin{array}{l}-0.0746 \\
(0.0716)\end{array}$ & $\begin{array}{l}-0.0492 \\
(0.0926)\end{array}$ \\
\hline Spain & $\begin{array}{l}-0.141^{*} \\
(0.0820)\end{array}$ & $\begin{array}{l}-0.00427 \\
(0.0773)\end{array}$ & $\begin{array}{c}0.125 \\
(0.107)\end{array}$ \\
\hline Song in own language & $\begin{array}{l}-0.0890 \\
(0.0879)\end{array}$ & $\begin{array}{l}-0.00801 \\
(0.0835)\end{array}$ & $\begin{array}{l}0.0587 \\
(0.177)\end{array}$ \\
\hline Ranking in stage [1-top] & $\begin{array}{l}0.00867 \\
(0.0385)\end{array}$ & $\begin{array}{c}0.0904^{* * *} \\
(0.0331)\end{array}$ & $\begin{array}{c}0.0365 \\
(0.0516)\end{array}$ \\
\hline Std. Dev. of Performance & $\begin{array}{l}-0.245 \\
(1.066)\end{array}$ & $\begin{array}{l}-0.293 \\
(1.061)\end{array}$ & $\begin{array}{c}2.168 \\
(1.860)\end{array}$ \\
\hline Reason: Default & $\begin{array}{c}-0.400^{* *} \\
(0.175)\end{array}$ & $\begin{array}{c}-0.0364 \\
(0.162)\end{array}$ & $\begin{array}{l}-0.0131 \\
(0.153)\end{array}$ \\
\hline Reason: Mistake & $\begin{array}{l}0.239^{* *} \\
(0.0926)\end{array}$ & $\begin{array}{c}0.0100 \\
(0.0907)\end{array}$ & $\begin{array}{l}0.0673 \\
(0.117)\end{array}$ \\
\hline Reason: Reciprocate & $\begin{array}{c}0.207 \\
(0.293)\end{array}$ & $\begin{array}{l}-0.192 \\
(0.247)\end{array}$ & $\begin{array}{c}0.133 \\
(0.257)\end{array}$ \\
\hline Reason: Strong & $\begin{array}{c}-0.0814 \\
(0.126)\end{array}$ & $\begin{array}{c}-0.0162 \\
(0.111)\end{array}$ & $\begin{array}{l}0.0947 \\
(0.159)\end{array}$ \\
\hline Past Winner is Last & & & $\begin{array}{l}0.0443 \\
(0.190)\end{array}$ \\
\hline Constant & $\begin{array}{c}0.407 \\
(0.450)\end{array}$ & $\begin{array}{l}-0.617 \\
(0.447)\end{array}$ & $\begin{array}{c}1.087 \\
(0.662)\end{array}$ \\
\hline $\begin{array}{l}\text { Observations } \\
\text { R-squared }\end{array}$ & $\begin{array}{c}177 \\
0.128\end{array}$ & $\begin{array}{c}175 \\
0.094\end{array}$ & $\begin{array}{c}52 \\
0.313\end{array}$ \\
\hline
\end{tabular}

